\title{
A spectrometric study of some sources of light
}

\section{A. Crova}

To cite this article: A. Crova (1878) A spectrometric study of some sources of light, Philosophical Magazine Series 5, 6:37, 314-316, DOI: 10.1080/14786447808639517

To link to this article: http://dx.doi.org/10.1080/14786447808639517

$$
\text { 曲 Published online: } 13 \text { May } 2009 .
$$

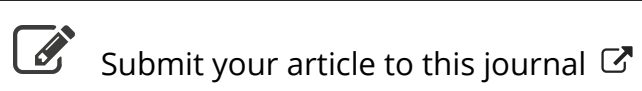

\footnotetext{
Џll Article views: 2
}

Q View related articles $\asymp$ 


\section{Intelligence and Miscellaneous Articles.}

A SPECTROMETRIC STUDY OF SOME SOURCES OF LIGHT.

BY A. CROVA.

THE general law of emission of the radiations emitted by a body

raised to an elevated temperature is not completely known. Dulong and Petit* have given the empirical law of the obscure radiations emanating from a body heated to temperatures below $240^{\circ}$; and Edm. Becquerel $\dagger$ has demonstrated that the intensity of the red, green, and blue radiations varies with the temperature of the body which emits them, according to an exponential law analogous to that of Dulong and Petit.

The exponentials which represent the law of emission of radiations of different refrangibilities are represented by curves of which the origin corresponds to the temperature at which the radiation considered commences to be produced, and rises the more rapidly as the wave-lengths of the radiations become less. According to M. Edm. Becquerel, the logarithms of the bases of these exponentials vary in the inverse ratio of the wave-lengths of the radiations.

These considerations may serve as a starting-point to a method of determination, in a spectrometric way, of the temperature of incandescent solids or liquids. In fact it follows from the investigations of Mr. Draper $\ddagger$ and M. Edm. Becquerel that, when the temperature of an incandescent solid increases in a continuous manner, the spectrum of the radiations emitted by it lengthens towards the violet end, and that each of the radiations of this spectrum is at the same time increased in intensity according to an exponential formula. The temperature of the luminous source can therefore be measured :-(1) by means of the wave-length of the radiation which limits the spectrum towards the violet; (2) by the position of the thermal maximum of the spectrum, which approaches nearer to the violet in proportion as the emission-temperature becomes higher; (3) by means of the ratio of the luminous intensity of a determinate radiation $\lambda$, taken in the spectrum of the source, to the intensity of the same radiation in the spectrum of a source of known temperature, compared with the ratio of the luminous intensities of another radiation $\lambda^{\prime}$ in the same two spectra.

These last determinations can be easily effected by means of a spectrophotometer. Several observers have made use of instruments of this kind $\S$. I used that of M. Glahn, which permits measurements to be made upon homogeneous radiations.

On the other hand, I have measured the thermal intensity of the simple radiations of the solar spectrum by means of a linear thermoelectric pile and a very sensitive galvanometer, using for the

* Ann. de Chimie et de Physique, 2 e série, t. vii.

† Edm. Becquerel, La Lumière, t. i. pp. 61-67.

$\ddagger$ Phil. Mag. 1847, vol. xxx. p. 345.

\$ Govi, Comptes Rendus, t. l. p. 156 (1860). Trannin, Journal de Physique, t. v. p. 297. Vierordt, Pogg. Ann. 5th series, vol, xx. Glahn, Wiedemann's Annalen, vol. i. (1877). 
first trials a flint-glass prism and a glass concave mirror silvered at its surface instead of an achromatic lens. The employment of a network of lines engraved on the metal instead of the prism would permit the influence of any elective absorption to be eliminated.

I have made numerous determinations of thermal curves of the solar spectrum on exceptionally tine days, at different periods in the years 1877 and 1878. These curves differ in the ratio of their respective ordinates, but especially in the position of the thermal maximum, as has been shown by Melloni. These curves were rendered comparable with one another by bringing them to the scale of the wave-lengths, and reducing, by means of the dispersion-curve of the prism, the intensities to those which would correspond to the theoretic case of the normal spectrum-that is, of constant dispersion.

The following are, for the luminous part of these spectra, the means of a number of concordant observations made under excellent atmospheric conditions:-

millim. millim. millim. millim. millim. millim. $\begin{array}{lllllllllll}\text { Wave-lengths } & \ldots . . . & 0.000676 & 0.000605 & 0.000560 & 0.000523 & 0.000486 & 0.000459\end{array}$

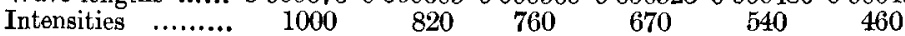

I have represented by 1000 the thermal intensity which corresponds to a red radiation of wave-length $0 \cdot 000676$ millim.; the intensities measured in the ultra-red cannot find a place in this Table, the corresponding wave-lengths not being accurately known.

Now here are the ratios of the luminous intensities of the same radiations of the spectra of the following sources, compared with the light of the sun :millim. millim, millim. millim. millim. millim. Wave-lengths ...... $0.000676 \quad 0.000605 \quad 0.000560 \quad 0.000523 \quad 0.000486 \quad 0.000459$ $\begin{array}{llllllll}\text { Electric light } \ldots . . . . & 1000 & 707 & 597 & 506 & 307 & 228\end{array}$ $\begin{array}{lllllll}\text { Drummond light... } & 1000 & 573 & 490 & 299 & 168 & 73\end{array}$ $\begin{array}{llllrrr}\text { Moderator lamp ... } & 1000 & \mathbf{4 4 2} & 296 & 166 & 80 & 27\end{array}$

The electric light was from 60 large Bunsen elements, Foucault regulator, with M. Carré's carbons in the focus of a metallic concave mirror; the Drummond light, oxygen and illuminating-gas thrown upon lime; the moderator lamp, fed with colza-oil. I measured the ratio of the intensity of each of the radiations of these spectra, corresponding to the wave-lengths of the preceding Table, to the intensity of the same radiation in the solar spectrum, representing these latter by the value of their thermal intensities, and always representing by 1000 the intensity corresponding to the wave-length 676 .

For luminous radiations which have undergone no weakening by previous transmission, there would be proportionality between the thermal and luminous intensities of one and the same radiation, whatever its origin, as MM. Jamin and Masson have demonstrated; but the experiments of M. Desains* have shown that, in the con-

* Comprtes Rendus, t. 1xvii. p. 297 . 
trary case, rays of the same wave-length, taken from different spectra, may have notably different properties.

We can, however, already state that, the intensity being the same in the red for the four spectra, the weakening towards the violet varies with each source, according to a certain function of the temperature; and without being able yet to attempt a measurement of this, we can already arrange them in the order of increasing temperatures :-moderator lamp ; stearine candle; illuminatinggas, of which I have not given the less-accordant Tables; Drummond light; electric light, and, lastly, the solar light, which corresponds to an emission-temperature much higher.than that of the electric light, in spite of the uncertainty caused by the absorptions it has undergone from its transmission through the gaseous envelopes of the sun and our atmosphere.

It will be possible to make rigorously exact measurement of the temperatures in the spectrometric way as soon as we know the precise law of emission for all the radiations and the numerical constants for each wave-length. The results contained in this Note may be regarded as a first essay towards the solution of this important question.-Comptes Rendus de l'Académie des Sciences, August 19, 1878, tome lxxxvii. pp. 322-325.

\section{ON THE EXCITATION OF ELECTRICITY BY PRESSURE AND FRICTION. BY H. FRITSCH, OF KÖNIGSBERG, PRUSSIA.}

1. It is well known that many crystalline bodies can be powerfully electrified by pressure. This, however, takes place in each case only under a perfectly definite condition. Calc-spar becomes electric only when pressed against another substance, never when pressed against another piece of calc-spar. Three pieces of calcspar were laid one upon another; a pressure was then exerted upon the uppermost, which would have made each of the pieces singly distinctly electric: the central piece proved to be quite devoid of excitation; only the two outer ones possessed the usual quantity of electricity. If two calc-spars were pressed against one another, the surfaces which were in contact with the foreign bodies by which the pressure was exerted exhibited electricity distinctly ; the two inner surfaces, where calc-spar had been in contact with calcspar, were without excitation. I have not yet succeded in carrying out the same experiment with other bodies.

2. According to previous observations, a definite substance, on undergoing friction against another, acquires always a certain invariable electrical excitation independent of the collateral circumstances, and accordingly the nature of the electricity excited is constantly the same. To test the correctness of this position the following experiments were instituted, in which the collateral circumstances were varied as much as possible.

a. With a violin-bow I stroked plates of zinc, copper, brass, and 